\title{
The hormone neuroparsin seems essential in Lepidoptera but not in
}

4 domesticated silkworms

6

8 Jan A. Veenstra ${ }^{1}$,

$10{ }^{1}$ INCIA UMR 5287 CNRS, University of Bordeaux, Pessac, France.

12 Corresponding Author:

Jan A. Veenstra ${ }^{1}$

14 INCIA UMR 5287 CNRS, Université de Bordeaux, allée Geoffroy St Hillaire, CS 50023, 33615

Pessac Cedex, France

16 Email address: jan-adrianus.veenstra@u-bordeaux.fr 


\section{Abstract}

The primary sequence of the Arthropod neurohormone neuroparsin is so variable that so far no

20 orthologs from moths and butterflies have been characterized, even though classical neurosecretory stains identify cells that are homologous to those producing this hormone in other insect species. Here

22 Lepidopteran cDNAs showing limited sequence similarity to other insect neuroparsins are described. That these cDNAs do indeed code for authentic neuroparsins was confirmed by in situ hybridization in

24 the wax moth, Galleria mellonella, which labeled the neuroparsin neuroendocrine cells. Although in virtually all genome assemblies from Lepidoptera a neuroparsin gene could be identified, the genome

26 assembly from the silkworm, Bombyx mori, has a neuroparsin gene containing a 16 nucleotide deletion that renders this gene nonfunctional. Although only a small number of all silkworm strains carry this

28 deletion, it suggests that the domestication of the silkworm has rendered the function of this neurohormone dispensable.

30

32

34 Key words: Neuroparsin - venus kinase receptor - Lepidoptera - Bombyx - silkworm - domestication 
bioRxiv preprint doi: https://doi.org/10.1101/716746; this version posted July 28, 2019. The copyright holder for this preprint (which was not certified by peer review) is the author/funder. All rights reserved. No reuse allowed without permission.

\section{Introduction}

In a 1928 publication Ernst Scharrer described what are now known as neuroendocrine cells

38 producing vasopressin and oxytocin (Scharrer, 1928). At the time the concept of what was later called neurosecretion and neuroendocrinology, but what at the time he called internal secretion ("innere

40 Sekretion”), was not readily accepted by vertebrate physiologists. However, insect physiologists had already demonstrated the existence of a "brain hormone" that activates the prothoracic gland (e.g.

42 Kopeć, 1922) and this strongly stimulated research on neurosecretory cells in insects. One of the most popular staining methods uses paraldehyde fuchsin, which stains several cells in the insect pars

44 intercerebralis that have axons projecting to the corpora cardiaca, where they release their products into the hemolymph. There are generally two different paraldehyde fuchsin cell types in the pars

46 intercerebralis, which differ by their staining intensity. We now know that the less intensely staining cells produce insect insulins and the other neuroparsins (Goltzené et al., 1992).

The structure of neuroparsin was first identified from Locusta migratoria (Girardie et al, 1989). Nevertheless, relatively little is known about the physiological relevance of this hormone in insects, no

50 doubt due in large part to its absence from Drosophila melanogaster (Veenstra, 2010), the insect neuropeptide model par excellence. In Locusta migratoria the hormone antagonizes juvenile hormone.

52 It delays vitellogenesis and immunoneutralization of neuroparsin accelerates vitellogenesis and induces green pigmentation. These effects are similar to those of juvenile hormone (Girardie et al., 1987). Once

54 its cDNA was cloned, neuroparsin was found to be expressed also outside the central nervous system (Lagueux et al., 1992) and the identification of several distinct cDNAs showed that they were derived

56 from a single gene that is alternatively spliced. The genome of L. migratoria revealed the neuroparsin gene to have seven coding exons that allow the production of five different neuroparsin transcripts

58 (Veenstra, 2014). Work on another migratory locust, Schistocerca gregaria, revealed a very similar situation, although the genome for this species has not yet been sequenced and so far only four different

60 neuroparsin transcripts have been identified (Girardie et al., 1998; Janssen et al., 2001; Claeys et al., 2003, 2005, 2006a,b). Interestingly, expression of the different transcripts is significantly different

62 between the solitary and gregarious phases in the latter species (Claeys et al., 2006a).

The extensive alternative splicing of neuroparsin transcripts seems to be limited to migratory

64 locusts, as to my knowledge it has not been found in other Arthropods. Some species, notably various Decapods (Veenstra, 2016) and blood sucking bugs like Rhodnius prolixus (KQ034340.1) and Cimex 
66 lectularis (Predel et al., 2018), however have multiple neuroparsin genes. In this respect neuroparsin resembles insulin, which in many species also has multiple genes. This is not the only similarity

68 between neuroparsin and insulin. Thus, both neuroparsin and insulin promote neurite outgrowth in locust brain (Vanhems et al., 1990). Furthermore, identification of ovarian ecdysteroid hormone from

70 the mosquito Aedes aegypti revealed it to be a neuroparsin ortholog (Brown et al., 1998) and the subsequent identification of a venus kinase as its receptor (Vogel et al., 2015) showed that insulin and neuroparsin use similar receptors in insects. In mosquitoes both hormones stimulate the ovary to produce ecdysteroids which in turn trigger vitellogenin synthesis by the fat body (Dhara et al., 2003).

74 Thus these two hormones seem somewhat complimentary. This is also suggested by venus kinase RNAi injections in S. gregaria, where both neuroparsin and insulin transcripts are upregulated .

76 Downregulation of the venus kinase receptor by RNAi leads to a delay in vitellogenin synthesis and strongly inhibits production of ecdysone and several of the enzymes needed for its synthesis.

78 Nevertheless, overall reproductive success appeared to be only slightly impacted in Schistocerca (Lenaerts et al., 2017).

The brains of Lepidoptera also typically contains two cell types that are stained by paraldehyde fuchsin (Panov and Kind, 1963) and Lepidopteran insulins have been extensively studied in the silkworm (for review see: Mizoguchi and Okamoto, 2013). However, in spite of much research on neuropeptides in the silkworm, and the presence of two venus tyrosine kinase receptors in its genome

84 (Vanderstraete et al., 2013), their putative ligands have so far escaped identification. I here show that neuroparsin seems ubiquitously present in Lepidoptera but that in some domesticated silkworm strains

86 the gene has mutated in such fashion that it can no longer be released as a hormone into the hemolymph.

88

\section{Materials and Methods}

90

\subsection{Bioinformatics}

92 After the initial identification of the Galleria and Bombyx neuroparsin genes 63 lepidopteran genome assemblies available at NCBI (https://www.ncbi.nlm.nih.gov/genome/?term=lepidoptera) were

94 analyzed for the presence of orthologous genes. Predicted neuroparsin precursors were deduced and the size of the intron between the first and second coding exons was determined. In most cases the three coding exons were found on the same contig, but in several genome assemblies the contigs are very 
small and in those cases the the coding exons were connected based on homology to produce a

98 neuroparsin precursor. In four assemblies no neuroparsin gene was found, in two of these species, Heliconius hecale and Heliothis virescens, the genes were assembled from individual reads recovered

100 from genomic SRAs, SRR7162651 and SRR5463746 respectively, using the sratoolkit (www.ncbi.nlm.nih.gov/sra/docs/toolkitsoft/) and Trinity (Grabherr et al., 2011) using a method

102 described previously (Veenstra, 2019).

\subsection{In situ hybridization}

The in situ hybridization protocol is based on a protocol provided by Dušan Žitňan for Drosophila as 106 described e.g. here (Kim et al., 2006). Dissections were done in $0.9 \% \mathrm{NaCl}$ and tissues were fixed in phosphate buffered 4\% paraformaldehyde for 2 hrs at room temperture in Eppendorf tubes. Tissues

108 were subsequently washed thrice for $30 \mathrm{~min}$ in PBS with $0.2 \%$ Tween 20 (PBST) and once for 30 min in $70 \%$ ethanol. After replacing the $70 \%$ ethanol the tissues were stored at $-20{ }^{\circ} \mathrm{C}$ for three to five days.

110 Tissues were next washed thrice for $25 \mathrm{~min}$ in PBST and then incubated with Proteinase K (50 $\mu \mathrm{g} / \mathrm{ml})$ in PBST for $30 \mathrm{~min}$. The proteinase $\mathrm{K}$ was stopped by washing the tissue for $30 \mathrm{~min}$ in glycin (2

$112 \mathrm{mg} / \mathrm{ml}$ ) in PBST, followed by two washes of $20 \mathrm{~min}$ in PBST. Next tissues were fixed a second time in phosphate buffered 4\% paraformaldehyde for $1 \mathrm{hr}$ followed by two washes in PBST for 20 min each.

114 This was followed by incubations for $20 \mathrm{~min}$ in 1:1 mixture of hybridization solution (HS: $50 \mu \mathrm{g} / \mathrm{ml}$ heparin, $100 \mu \mathrm{g} / \mathrm{ml}$ salmon testes DNA, $750 \mathrm{mM} \mathrm{NaCl}, 75 \mathrm{mM}$ sodium citrate, in deionized RNase free water, pH 7.0, 50\% deionized formamide, 0.1 \% Tween 20) and PBST, followed by 25 min in HS, both at roomtemperature. HS was then replaced with fresh HS and the tissues were incubated for 3 hrs at 48

$118{ }^{\circ} \mathrm{C}$, after which HS was replaced with fresh HS containing $10 \%$ of digoxygenin hybridization probe which had previously been brought to $95{ }^{\circ} \mathrm{C}$ for either $3 \mathrm{~min}$, in case of a previously used probe, or 45

120 min when a hybridization probe is used for the first time. Hybridization was carried out overnight at 48 ${ }^{\circ} \mathrm{C}$. The following day hybridization probe was recovered and stored at $-20{ }^{\circ} \mathrm{C}$ for future use. Tissues

122 are washed in fresh HS four times, thrice for 2 to $2.5 \mathrm{hrs}$, and then overnight, all washes in HS were done at $48{ }^{\circ} \mathrm{C}$. The next day tissues were brought to room temperature and washed in a 1:1 mixture of

124 PBST and HS, follwed by three 20 min washes in PBST at room temperature. Next tissues were saturated with 1\% BSA in PBST for $1 \mathrm{hr}$. The 1\% BSA in PBST was then used to dilute sheep anti126 digoxygenin Fab-fragments conjugated to alkaline phosphatase (1:1000, Sigma-Aldrich) in which the tissues were incubated overnight at room temperature. Next morning tissues were washed thrice 20 min 
128 with PBST, followed by three washes in freshly prepared alkaline phosphate buffer (APB, $100 \mathrm{mM}$ Tris, $50 \mathrm{mM} \mathrm{MgCl2,} 100 \mathrm{mM} \mathrm{NaCl}$, pH 9.5 and 0.1\% Tween 20). During the last wash, the tissues

130 were transferred to small glass dissection dishes and then the location of the digoxygenin probe was visualized by replacing the wash solution with APB containing $20 \mu \mathrm{l} / \mathrm{ml}$ of a commercial NBT/BCIP

132 stock solution (Sigma-Aldrich, $18.75 \mathrm{mg} / \mathrm{ml}$ nitro blue tetrazolium chloride and 9.4 mg/ml 5-bromo-4chloro-3-indolyl-phosphate, toluidine-salt in 67\% DMSO). Color development was followed under a

134 dissecting microscope and took about five minutes. Once color development was judged satisfactory, the alkaline phosphatase was stopped by changing the staining solution with $100 \mathrm{mM}$ phosophate

136 buffer, $\mathrm{pH}$ 7.0. This was followed by four $15 \mathrm{~min}$ washes in increasing concentrations of glycerol (20 $\%, 40 \%, 60 \%$ and $80 \%$ ) and finally tissues were mounted between a slide and a coverslip in $80 \%$

138 glycerol. All incubations at room temperature were performed on gently rotating orbital shaker.

\section{2.3. Hybridization probes}

RNA was extracted and reverse transcribed using random primers and M-MuLV reverse transcriptase

142 (New England Biolabs) and a PCR product of about 300 nucleotides from a coding sequence was than amplified by PCR using Q5® High-Fidelity DNA polymerase (New England Biolabs). The resulting

144 PCR products were gel purified, quantified and their identities as authentic neuroparsin cDNAs confirmed by automated Sanger sequencing. Sense and anti-sense digoxigenin labeled probes were

146 then produced using Taq polymerase (New England Biolabs) and 40 cycles of PCR with either the sense or anti-sense primer in a Taq polymerase PCR mixture to which $0.067 \mathrm{mM}$ of Digoxigenin-5-

148 aminoallyl-dUTP (Jena Bioscience GmbH, Jena, Germany) had been added and in which the concentration of dTTP had been lowered to $0.133 \mathrm{mM}$. The final PCR product was used directly in the 150 in situ hybridization procedure.

\section{2.4. Primer sequences used}

Galeria neuroparsin

154 forward primer 5'-CGAGTGTCCAGTATGCATCG-3' reverse primer 5'-TTGGGATTAAGGAGCCATTG-3'

156 Bombyx neuroparsin forward primer 5'-GAGAGACGAACCGGAAATCA-3'

158 reverse primer 5'-CCATGCCTTGACAGATACCC-3' 


\subsection{Insects}

Galleria mellonella larvae were purchased from St. Laurent (La Chapelle Saint Laurent,

162 France), while Bombyx mori pupae were a generous gift from Michal Žurovec from the University of Southern Bohemia.

164

\section{Results}

Extensive use of the BLAST program led to the identification of a neuroparsin precursor candidate that had very limited sequence homology with its orthologs from other species (Fig. 1), but that within the Lepidoptera is relatively well conserved (Fig. 2 and Table S1). It typically has a signal peptide and analysis of a limited number of RNAseq SRAs from B. mori (Table S2) suggested it to be

170 relatively specific for the brain.

Several of the Lepidopteran genome assemblies are little more than first drafts and it is

172 therefore not surprising that I was unable to find evidence for a neuroparsin gene in Operophtera brumata. On the other hand there is abundant genomic and transcriptome data for Plutella xylostella

174 (see e.g. http://dbm.dna.affrc.go.jp/px/). This species is one of two studied here that does not belong to the Apoditrysia taxon. The other one is Eumeta japonica, and its neuroparsin precursor sequence is

176 very different from that of the Apoditrysia (Fig. 1). Hence it seems plausible that the Plutella neuroparsin sequence was not recognized because it is too different from that of the other Lepidoptera.

To confirm or invalidate the hypothesis that these sequences might represent neuroparsin orthologs, whole mount in situ hybridization of brains was performed in Galleria mellonella larvae as

180 well as adults. RNA extraction of Galleria heads and is subsquent reverse transcription allowed the production of a neuroparsin PCR product the identity of which was confirmed by Sanger sequencing

182 (Figs. S1,S2). In both larvae and adults in situ hybridization revealed two bilateral groups of four large cells in the pars intercerebralis (Fig. 3) in the location where neuroparsin expressing cells were expected based on paraldehyde fuchsin staining reports (Panov and Kind, 1963). RNA extraction of a single Bombyx brain and is subsquent reverse transcription similarly allowed the production of a neuroparsin PCR product that was sequenced and found to have the 16 base pair solution (Figs. S3,S4). Although in situ hybridization procedures were identical to those performed on Galleria, which were run in parallel, no in situ hybridization signal was obtained in Bombyx adult brains. This could be due to low expression levels of neuroparsin in B. mori, as suggested by the 0.00 TPM (transcripts per 
million) values for the two brain RNAseq transcripts present at silkbase (http://silkbase.ab.a.utokyo.ac.jp). Digoxigenin probes generated with the sense probes did not yield any signal in either 192 species.

Intriguingly in the Bombyx mori genome assembly, the neuroparsin gene does not code for a

194 signal peptide. However, a signal peptide is predicted from the orthologous B. mandarina gene (Fig. 4), the species from which B. mori was domesticated about 5,000 years ago (Sun et al., 2012; Chen et al.,

196 2019). There are two significant differences between the two genes. The first one concerns the intron between the first and second coding exons. In the domesticated silkworm genome assembly it contains

1989,493 but that of the wild silkworm has only 827 base pairs. The second and more important difference is a unique deletion of 16 base pairs from the first coding exon (Fig. 4). Analysis of B. mori brain

200 RNAseq SRAs yielded a total of 4,358 spots and Trinity unambiguously confirmed the proposed mRNA. This mRNA contains the unique deletion, as was expected since these RNAseq SRAs are all 202 obtained from the same strain as used for genome sequencing.

The deletion of 16 base pairs from the first coding exon either leads to a very small peptide with

204 a signal sequence or, in case the first three methionine codons were to be ignored, to a protein that contains the neuroparsin sequence, but lacks a signal peptide (Fig. 4). Therefore this mutation makes it

206 impossible for the neuroendocrine cells expressing this mutated neuroparsin gene to secrete this neurohormone. Over time a large number of different silkworm strains have been sequenced, in order

208 to analyze the domestication of the silkworm and and its underlying evolutionary process (Xia et al., 2009; Xiang et al., 2018). Sequences for still other lines are available at silkbase (http://silkbase.ab.a.u-

210 tokyo.ac.jp). Although the latest B. mori genome assembly (Kawamoto et al., 2019) shows a 16 basepair deletion in the neuroparsin coding sequence, only a limited number of silkworm strains have

212 this deletion. Thus in the 161 different B. mori strains in which this could be determined, there were only twelve that carried the 16 base pair deletion while four other strains had both alleles. As genome

214 assemblies are all based on single individuals, the actual number of $B$. mori strains where this allele is present is almost certainly larger, but it must be a minority. These numbers are not consistent with the

216 Hardy-Weinberg equilibrium and, hence, in most populations the allele will be fixed.

It seemed interesting to know whether the enormous increase in size of the intron between the

218 first and second coding exons might be of functional significance. I therefore determined, where possible, the size of this intron in other Lepidopteran genomes, as well as the various Bombyx strains.

220 Whereas it was relatively easy to determine coding sequences in genome assemblies with large 
numbers of small contigs, the determination of the size of this intron is more difficult. Nevertheless,

222 there were only a few species in which the size of this intron could not be determined. In the large majority of species, this intron is quite small, and there are only a few species where it is larger than

2241500 base pairs; the largest intron was found in Tuta absoluta (2285, Table S1). Determining the size of the intron in all the Bombyx strains was more difficult, in five B. mandarina strains where this could be

226 determined it varied between 827 and 1292. In the thirty B. mori strains where this could be established it varied between 918 and 1298; none of these strains had the 16 base pair deletion. There was not a

228 single $B$. mori strain having this deletion for which it was possible to determine the size of the intron, apart from the of the official sequence assembly of the p50T strain (Kawamoto et al., 2019).

230 Nevertheless, in several strains its size had to be at least more than 1900 base pairs and this was found both in strains that have the 16 basepair deletion and strains that do not. Although this suggests that the

232 intron size increased before the deletion occurred, it does not definitively prove it.

\section{4. Discussion}

Bombyx mori has been and still is the model for lepidopteran neuropeptides and it was surprising that neuroparsin that seemed to be produced in large neuroendocrine cells of the brain had escaped detection in this species as well as other Lepidoptera. It is now clear that Lepidoptera do have such a hormone, but its sequence is so different from that of other Arthropod neuroparsins, that it is

240 difficult to recognize as such. Nevertheless, the expression in Galleria brain neuroendocrine cells of this protein confirms that it is indeed neuroparsin.

242 In the Bombyx strain used preferentially in the laboratory and the one with the best genome assembly (Kawamoto et al., 2019) the neuroparsin gene shows two mutations. The first one makes it

244 impossible for the putative neuroparsin precursor to have a signal peptide and hence it can not be released as a hormone into the hemolymph. Although, it is also possible that no neuroparsin is made at

246 all, and that only small peptide with a signal peptide is the protein product made from this gene. Either way, this probably explains why neuroparsin has not previously been identified from this species.

It is interesting to note, that there is second mutation in the Bombyx neuroparsin gene, which concerns a very significant increase in the size of the intron between the first and second coding exons.

250 In those moths and butterfies where its size could be determined it was never more than 2285, and in most of them it was less than 1000 base pairs. Yet in the sequenced B. mori strain it is 9493 base pairs 
252 long. It is noticeable that neuropeptide genes that are heavily expressed in small number of neurons, such as the insulins, AKHs, or the Locusta vasopressin genes, all seem to have very small introns,

254 suggesting that small intron sizes may facilitate efficient neuropeptide production. It seemed possible that once a 16 base pair deletion effectively inactivated the neuroparsin gene there was no longer any

256 selection for maintaining the small size of this intron. Alternatively, if for some unknown reason the neuroparsin gene has no function in domesticated silkworms, the increase of the size of this intron may

258 have preceded the deletion. Results suggested that the deletion in the coding sequence occurred after the increase of the intron size. If one accepts the notion that small intron sizes facilitate efficient

260 expression of (neuropeptide) genes, it then also suggests that during domestication the importance of the neuroparsin gene was diminished well before the gene was completely inactivated by the deletion

262 in its coding region. Such a scenario may explain the absence of a detectable in situ hybridization signal in B. mori.

264 It is indeed surprising, that while in virtually all Lepidopteran genomes a neuroparsin gene can be detected that seems to be functional, it is only in some domesticated Bombyx strains that this gene

266 has apparently become superfluous. It is well documented that domestication leads to significant changes in the genome of a species and this also occurred in the silkworm (Xiang et al., 2018). As this mutated gene is only present in some but not all domesticated silkworms it is clearly not a mutation that facilitated domestication, it is rather a gene that domesticated silkworms can do without, while 270 remaining essential in wild moths.

It is obvious that just like Drosophila melanogaster the domesticated silkworm survives well 272 without a functional neuroparsin gene. It can thus not be excluded that it is a pure coincidence that this happened in some domesticated strains of Bombyx mori and not in other Lepidoptera, assuming that the

274 absence of the gene in Plutella xylostella and Operophtera brumata is indeed due to technical problems rather than a genuine absence from their genomes.

276 A recent publication on Anopheles coluzzii showed the venus kinase receptor to be required for protection against infection by Plasmodium parasites (Gouignard et al., 2019). As the venus kinase

278 receptor can also be activated by L-amino acids (e.g. Ahier et al., 2009), this does not necessarily show the implication of neuroparsin. Nevertheless, within in this context it is at least intriguing to note that

280 some of the species with the largest intron sizes all have some type of natural exterior protection during the larval stages which not only makes chemical control of such species difficult, but likely also

282 protects them against viruses, bacteria and perhaps parasites. Thus Cydia pomonella (intron size 1598, 
Table S1) larvae live and feed inside apples, larvae of Galleria mellonella (intron size 1884, Table S1)

284 live inside bee hives, Tuta absoluta (intron size 2285, Table S1) is a leaf miner and caterpillars of Megathymus ursus (intron size 1549, Table S1) feed inside yucca roots and agave leaves (Cong et al., 2019). In any case, a hormone that would be important for protection against parasites or infections, would likely be less important in a domesticated species, as diseased animals would be rapidly eliminated by silk farmers.

The identification of Lepidopteran neuroparsins shows how variable its structure can be in

290 insects and it illustrates the difficulty of finding putative orthologs of this hormone in other Arthropods. Although not limited to insects as the Decapod neuroparsins convincingly show, it remains unknown whether this hormone is present in other Arthropods like e.g. Chelicerates. Venus kinase receptors have a wide distribution within Protostomes and even Deuterostomes (Vanderstraete et al., 2013; Dissous et al., 2014). Since neuroparsin can activate this type of receptor (Vogel et al., 2015), a priori, one might expect neuroparsin orthologs to have a similar wide distribution. However, these receptors are also activated by amino acids (e.g. Ahier et al., 2009; Vanderstraete et al., 2014; Gouignard et al., 2019) and hence the distribution of neuroparsins could be much more limited. It is therefore regrettable that the extreme variability of this hormone in insects suggests, that it will be very difficult to identify neuroparsin orthologs, if they even exist.

Acknowledgements. I thank Michal Žurovec for Bombyx mori pupae and Dušan Žitňan for his in situ hybridization protocol.

References

306 Ahier, A., Rondard, P., Gouignard, N., Khayath, N., Huang, S., Trolet, J., Donoghue, D.J., Gauthier, M., Pin, J.P., Dissous, C. 2009. A new family of receptor tyrosine kinases with a venus flytrap binding

308 domain in insects and other invertebrates activated by aminoacids. PLoS One 4:e5651. doi: 10.1371/journal.pone.0005651.

Brown, M.R., Graf, R., Swiderek, K.M., Fendley, D., Stracker, T.H., Champagne, D.E., Lea, A.O. 312 1998. Identification of a steroidogenic neurohormone in female mosquitoes. J. Biol. Chem. 273:39673971. doi:10.1371/journal.pone.0017274.

314

Chen, D.B., Zhang, R.S., Bian, H., Li, Q., Xia, RX., Li, YP., Liu YQ., Lu, C.. 2019. Comparative 316 mitochondrial genomes provide new insights into the true wild progenitor and origin of domestic silkworm Bombyx mori. Int. J. Biol. Macromol. 131:176-183. doi: 10.1016/j.ijbiomac.2019.03.002. 
bioRxiv preprint doi: https://doi.org/10.1101/716746; this version posted July 28, 2019. The copyright holder for this preprint (which was not certified by peer review) is the author/funder. All rights reserved. No reuse allowed without permission.

320

322

324

326

328

330

332

334

336

338

340

342

344

346

348

350

352

354

356

358

360

362

364

Claeys, I., Simonet, G., Van Loy, T., De Loof, A., Vanden Broeck, J. 2003. cDNA cloning and transcript distribution of two novel members of the neuroparsin family in the desert locust, Schistocerca gregaria. Insect Mol. Biol. 12:473-481. doi:10.1046/j.1365-2583.2003.00431.x.

Claeys, I., Simonet, G., Breugelmans, B., Van Soest, S., Franssens ,V., Sas, F., De Loof, A., Vanden Broeck, J. 2005. Quantitative real-time RT-PCR analysis in desert locusts reveals phase dependent differences in neuroparsin transcript levels. Insect Mol. Biol.14:415-422. doi:10.1111/j.13652583.2005.00572.x.

Claeys, I., Breugelmans, B., Simonet, G., Franssens, V., Van Soest, S., Vanden Broeck J. 2006a. Regulation of Schistocerca gregaria neuroparsin transcript levels by juvenile hormone and 20hydroxyecdysone. Arch. Insect Biochem. Physiol. 62:107-115. doi:10.1002/arch.20127.

Claeys, I., Breugelmans, B., Simonet, G., Van Soest, S., Sas, F., De Loof, A., Vanden Broeck, J. $2006 \mathrm{~b}$. Neuroparsin transcripts as molecular markers in the process of desert locust (Schistocerca gregaria) phase transition. Biochem. Biophys. Res. Commun. 341:599-606. doi:10.1016/j.bbrc.2006.01.011.

Cong, Q., Li, W., Borek, D., Otwinowski, Z., Grishin, N.V. 2019. The Bear Giant-Skipper genome suggests genetic adaptations to living inside yucca roots. Mol. Genet. Genomics. 2019 Feb;294(1):211226. doi: 10.1007/s00438-018-1494-6.

Dhara, A, Eum, J.H, Robertson, A., Gulia-Nuss, M., Vogel, K.J., Clark, K.D., Graf, R., Brown, M.R., Strand, M.R. 2013. Ovary ecdysteroidogenic hormone functions independently of the insulin receptor in the yellow fever mosquito, Aedes aegypti. Insect Biochem. Mol. Biol. 43:1100-1108. doi: 10.1016/j.ibmb.2013.09.004.

Dissous, C, Morel, M, Vanderstraete, M., 2014. Venus kinase receptors: prospects in signaling and biological functions of these invertebrate kinases. Front. Endocrinol. 5:72. doi: 10.3389/fendo.2014.00072.

Girardie, J., Bourême, D., Couillaud, F., Tamarelle, M., Girardie, A., 1987. Anti-juvenile hormone effect of neuroparsin A, a neuroprotein isolated from locust corpora cardiaca. Insect Biochem. 17, 977983. doi:10.1016/0020-1790(87)90106-5.

Girardie, J., Girardie, A., Huet, J.C., Pernollet, J.C. 1989. Amino acid sequence of locust neuroparsins. FEBS Lett. 245:4-8. doi:10.1016/0014-5793(89)80179-6.

Girardie, J., Huet, J.C,, Atay-Kadiri, Z., Ettaouil, S., Delbecque, J.P., Fournier, B., Pernollet, J.C., Girardie, A. 1998. Isolation, sequence determination, physical and physiological characterization of the neuroparsins and ovary maturing parsins of Schistocerca gregaria. Insect Biochem. Mol. Biol. 28:641650. doi:10.1016/S0965-1748(98)00053-8.

Goltzené, F., Holder, F., Charlet, M., Meister, M., Oka, T. 1992. Immunocytochemical localization of Bombyx-PTTH-like molecules in neurosecretory cells of the brain of the migratory locust, Locusta migratoria. A comparison with neuroparsin and insulin-related peptide. Cell Tissue Res. 269:133-140. doi:10.1007/BF00384733. 
366 Gouignard, N., Cherrier, F., Brito-Fravallo, E., Pain, A., Zmarlak, N.M., Cailliau, K., Genève, C., Vernick, K.D., Dissous, C., Mitri, C. 2019. Dual role of the Anopheles coluzzii Venus Kinase Receptor in both larval growth and immunity. Sci. Rep. 9:3615. doi: 10.1038/s41598-019-40407-x.

370 Grabherr, M.G., Haas, B.J., Yassour, M., Levin, J.Z., Thompson, D.A., Amit, I., Adiconis, X., Fan, L., Raychowdhury, R., Zeng, Q., Chen, Z., Mauceli, E., Hacohen, N., Gnirke, A., Rhind, N., di Palma, F.,

372 Birren, B.W., Nusbaum, C., Lindblad-Toh, K., Friedman, N., Regev, A. 2011. Full-length transcriptome assembly from RNA-Seq data without a reference genome. Nat. Biotechnol. 29:644-652.

Janssen, T., Claeys, I., Simonet, G., De Loof, A., Girardie, J., Vanden Broeck, J. 2001. cDNA cloning

gregaria. Insect Mol. Biol. 10:183-189. doi:10.1046/j.1365-2583.2003.00431.x.

Kawamoto, M., Jouraku, A., Toyoda, A., Yokoi, K., Minakuchi, Y., Katsuma, S., Fujiyama, A., Kiuchi,

T., Yamamoto, K., Shimada, T. 2019. High-quality genome assembly of the silkworm, Bombyx mori. Insect Biochem. Mol. Biol.107:53-62. doi: 10.1016/j.ibmb.2019.02.002.

Kim, Y.J., Žitňan, D., Galizia, C.G., Cho, K.H., Adams, M.E., 2006. A command chemical triggers an innate behavior by sequential activation of multiple peptidergic ensembles. Curr. Biol. 16:13951407.doi: 10.1016/j.cub.2006.06.027.

Kopeć, S., 1922. Studies on the necessity of the brain for the inception of insect metamorphosis. Biol. Bull. 42: 323-342. doi:10.2307/1536759.

Lagueux, M., Kromer, E., Girardie, J. 1992. Cloning of a Locusta cDNA encoding neuroparsin A. Insect Biochem. Mol. Biol. 22:511-516. doi:10.1016/0965-1748(92)90027-C.

Lenaerts, C., Palmans, J., Marchal, E., Verdonck, R., Vanden Broeck, J. 2017. Role of the venus kinase receptor in the female reproductive physiology of the desert locust, Schistocerca gregaria. Sci. Rep. 7:11730. doi: 10.1038/s41598-017-11434-3.

Mizoguchi, A., Okamoto, N. 2013. Insulin-like and IGF-like peptides in the silkmoth Bombyx mori: discovery, structure, secretion, and function. Front. Physiol.4: 217. doi: 10.3389/fphys.2013.00217.

400 Панов, А.А., Кинд, Т.В. , 1963. Система нейросекреторных клеток головного мозга чешуекрылых (Lepidoptera, Insecta). Докл. Акад. наук CCСР 153:1186-1189.

Predel, R., Neupert, S., Derst, C., Reinhardt, K., Wegener, C. 2018. Neuropeptidomics of the bed bug 404 Cimex lectularius. J. Proteome Res. 17:440-454. doi: 10.1021/acs.jproteome.7b00630.

406 Scharrer, E. 1928. Die Lichtempfindlichkeit blinder Elritzen. Z. vergl. Physiol. 7:1-38.

408 Sun, W., Yu, H., Shen, Y., Banno, Y., Xiang, Z., Zhang, Z. 2012. Phylogeny and evolutionary history of the silkworm. Sci. China Life Sci. 55:483-96. doi: 10.1007/s11427-012-4334-7. 
bioRxiv preprint doi: https://doi.org/10.1101/716746; this version posted July 28, 2019. The copyright holder for this preprint (which was not certified by peer review) is the author/funder. All rights reserved. No reuse allowed without permission.

412

414

416

418

420

422

424

426

428

430

432

434

436

438

440

442

444

446

448

450

452

454

Vanderstraete, M., Gouignard, N., Ahier, A, Morel, M., Vicogne, J., Dissous, C. 2013. The venus kinase receptor (VKR) family: structure and evolution. BMC Genomics 14:361. doi:10.1186/1471-2164-14361.

Vanderstraete, M., Gouignard, N., Cailliau, K., Morel, M., Hahnel, S., Leutner, S., Beckmann, S., Grevelding, C.G., Dissous, C. 2014. Venus kinase receptors control reproduction in the platyhelminth parasite Schistosoma mansoni. PLoS Pathog. 10:e1004138. doi: 10.1371/journal.ppat.1004138.

Vanhems, E., Delbos, M., Girardie, J. 1990. Insulin and neuroparsin promote neurite outgrowth in cultured locust CNS. Eur. J. Neurosci. 2:776-782. doi:10.1111/j.1460-9568.1990.tb00468.x.

Veenstra, J.A. 2010. What the loss of the hormone neuroparsin in the melanogaster subgroup of Drosophila can tell us about its function. Insect Biochem. Mol. Biol. 40:354-361. doi:

10.1016/j.ibmb.2010.03.001.

Veenstra, J.A. 2014. The contribution of the genomes of a termite and a locust to our understanding of insect neuropeptides and neurohormones. Front. Physiol. 5:454. doi: 10.3389/fphys.2014.00454.

Veenstra, J.A. 2016. Similarities between decapod and insect neuropeptidomes. PeerJ. 4:e2043. doi: 10.7717/peerj.2043.

Veenstra, J.A. 2019. Two Lys-vasopressin-like peptides, EFLamide, and other phasmid neuropeptides. Gen. Comp. Endocrinol. 278:3-11. doi: 10.1016/j.ygcen.2018.04.027.

Vogel, K.J., Brown, M.R., Strand, M.R. 2015. Ovary ecdysteroidogenic hormone requires a receptor tyrosine kinase to activate egg formation in the mosquito Aedes aegypti. Proc. Natl. Acad. Sci. USA. 112:5057-5062. doi: 10.1073/pnas.1501814112.

Xia, Q., Guo, Y., Zhang, Z., Li, D., Xuan, Z., Li, Z., Dai, F., Li, Y., Cheng, D., Li, R., Cheng, T., Jiang, T., Becquet, C., Xu, X., Liu, C., Zha, X., Fan, W., Lin, Y., Shen, Y., Jiang, L., Jensen, J., Hellmann, I., Tang, S., Zhao, P., Xu, H., Yu, C., Zhang G., L,i J., Cao, J., Liu, S., He, N., Zhou, Y., Liu, H., Zhao, J., Ye, C., Du, Z., Pan, G., Zhao, A., Shao, H., Zeng, W., Wu, P., Li, C., Pan, M., Li, J., Yin, X., Li, D., Wang, J., Zheng, H., Wang, W., Zhang, X., Li, S., Yang, H., Lu, C., Nielsen, R., Zhou, Z., Wang, J., Xiang, Z., Wang, J. 2009. Complete resequencing of 40 genomes reveals domestication events and genes in silkworm (Bombyx). Science. 326:433-436. doi: 10.1126/science.1176620.

Xiang, H., Liu, X., Li, M., Zhu, Y., Wang, L., Cui, Y., Liu, L., Fang, G., Qian, H., Xu, A., Wan,g W., Zhan, S. 2018. The evolutionary road from wild moth to domestic silkworm. Nat. Ecol. Evol. 2:12681279. doi: 10.1038/s41559-018-0593-4.

\section{Legends to the figures}

Fig. 1. Alignment of selected Arthropod neuroparsin precursor sequences. Sequences are from Tischeria quercitella (GENO01134828.1), Eumeta japonica (BGZK01000877.1; join[241322..241488,242249..242387,243576..243797]), Galleria mellonella (XM_026905025), 
bioRxiv preprint doi: https://doi.org/10.1101/716746; this version posted July 28, 2019. The copyright holder for this preprint (which was not certified by peer review) is the author/funder. All rights reserved. No reuse allowed without permission.

Bombyx mandarina (XM_028184972.1), Aedes aegypti (U69542.1), Tribolium castaneum (XM_015980588), Apis mellifera (XM_026440542), Locusta migratoria (Y17710.1), Procambarus clarkii (GARH01002923.1) and Carcinus maenas (GFYV01020843.1). Note the very limited sequence similarity of the Lepidopteran neuroparsins with those from other Arthropods. Primary sequence similarity is so poor that Clustal Omega no longer aligns the cysteine residues, which are highlighted in red; other conserved amino acid residues are highlighted in black.

Fig. 2. Alignment of selected Lepidoptera neuroparsin precursor sequences. Sequences are from Spodoptera litura (GBBY01013502.1), Helicoverpa armigera (GFWI01343101.1), Pieris rapae (GGJY01013372.1), Danaus plexippus (OWR50203.1), Papilio machaon (XP_014372220.1), Galleria mellonella (XM_026905025), Manduca sexta (GETI01101303.1) and Bombyx mandarina (XM_028184972.1). For more sequences see Table S1. Cysteine residues are highlighted in red and other conserved amino acid residues in black.

470 Fig. 3. In situ hybridization of neuroparsin mRNA in the brain of Galleria mellonella larva (a), and adult (b) with an amplification of the adult pars intercerebralis in (c). Note that these are whole mounts and consequently it is difficult to get all cells in focus in a single picture. Scale bars are $500 \mu \mathrm{m}$ in (a) and (b) and $200 \mu \mathrm{m}$ in (c).

Fig. 4. Bombyx neuroparsin genes. a. Comparative structure of the Bombyx neuroparsin genes as 476 present in the genome assemblies. Green and purple indicate exons, green the untranslated and purple the translated parts. The numbers in the purple boxes and below the introns indicate their sizes in base pairs. Both genes have four exons, of which first is untranslated. TATA indicates the location of the TATA box. Note the large difference in the size of the intron between the first and second coding exon.

480 Two different possible translations of the B. mori mRNA are represented, that would yield very different translated proteins. b. Direct comparison of the second exon (capitals) and the sequences 482 immediately surrounding them (lower case). The start codon is indicated by an arrow. Note that apart from two SNPs, one before the start codon and one that causes a ile-val change, there is a 16 nucleotide 484 deletion in the $B$. mori sequence. $\mathbf{c}$. The possible translations of the two genes. In $B$. mandarina a conventional neuroparsin precursor is predicted. In B. mori, one predicts a very short peptide without any sequence similarity to neuroparsin but with a signal peptide. In case the first three start codons 
were to be ignored, a protein could be produced that has a neuroparsin sequence, but lacks that a signal 488 peptide and hence can not be expected to be secreted. Black highlighting indicates identical amino acid residues. 
490 Figure 1.

\author{
Tischeria \\ Eumeta \\ Galleria \\ B.mandarina \\ Aedes \\ Tribolium \\ Apis \\ Locusta \\ Carcinus \\ Procambarus
}

Tischeria

Eumeta

Galleria

B. mandarina

Aedes

Tribolium

Apis

Locusta

Carcinus

Procambarus

Tischeria

Eumeta

Galleria

B. mandarina

Aedes

Tribolium

Apis

Locusta

Carcinus

Procambarus

Tischeria

Eumeta

Galleria

B. mandarina

Aedes

Tribolium

Apis

Locusta

Carcinus

Procambarus

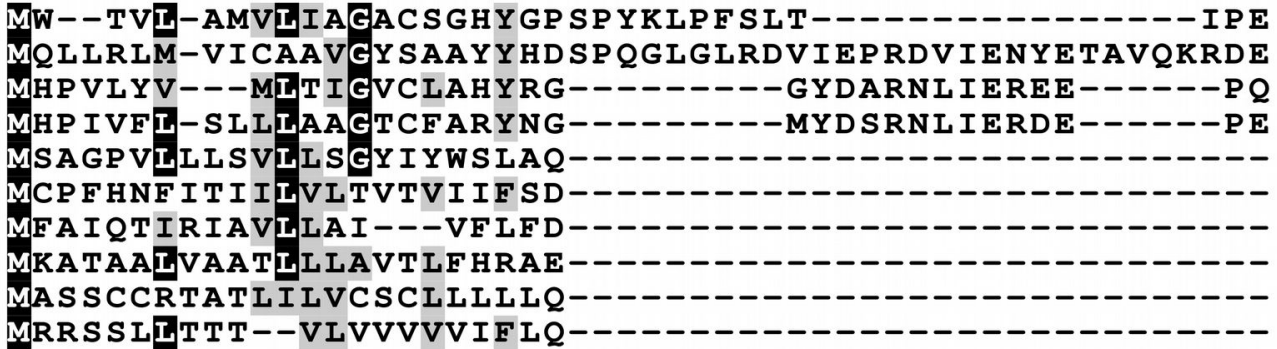

KLVEPKLVECPVCRLESS I ECEPF----DSVEGRKMLKKCRHGTFPNTMCNN YVLQLELVACPVCDQF-------LDDECTVLKNGKRYKKCAFGTYINEVCGN DD IEGE IVECPVCIGSSSNDWLP SNE L CP IVRGNKRYKRCQRGTYVNTVCDN INGDME IVECPVCED--SGHWLTSNEVCTIVKGHRKYKK CDHGTYINEVCGN TNVIEIR--CKL----------------YSGPAVQNTGECVHGAE-INP CGK KGT AMIHLPCKRC-AT------------IQECNADP PQLCVFGEN-RDYCNR KCSGYPS--IRQGTTS-----------YCLGCGDSCHKCKYGI AMSSACGI RNP I SRS--CE------------------GANCVVDITR CEY GDV-T DF F GR EAS GAPR--CD-----------------RHDEE-APKN CKY GTT-QDWCKN GTAGAP R--CS------------------RQGGRAP P HNCKYGTV-SDWCGN

KTDCYRGPGESCNED-----EGIHCVP SLWCNNYVCKGT SDTGAATKTHSLD QRDCYRGPKQYCTEKMAEDKLGAKCAHGYTCNAQLHECVG---LFNELDSLQ RLDCYRGPKG OCTEKMDF DIYGQKCAPGYYCNKYLGVCTG---LEYNVESKT RRDCFRGP GEQCTEKMEFDTYGQKCAPGYYCNKPMGICQG---MDYVLDSNE -ISCLKGVGDKCGFSTAGI IMSGKCASGLMCCG--GQCVGCKNGI--CDHRL -RVCSKGPGEKCGDRF---NIIGTCGEGLWCSNKDNRCHGCY I P TMAC----VQCAKGPDEL CGGPQ---NYLGI CAEGMQCSC--NKCI GCSAEKFECSKTS -KVCAKGP GDKCGGPY---ELHGKCGVGMDCRC--GLCSGCSLHNLQCFFFE -GVCAKGPGETCGGYR---WSEGKCGEGTFCSC--GICGGCSPFDGKCGP--PVCAKGPGETCGGEW---GENGACGAGTYCSC--GFCSGCSANL-ECWF--

TFLYPVTWRNGFQ

LAGLRHYYIIPEDNTNSYIDKYRIARSHHLY QWLLNPNRRYPLRAKRDV

LFILNP HRRYSLQRNTLKGPMSHSLLDAIRN

CP P RLTMNHHP F GL GLMAGSP QQQQPVGVF P S L YKMF DYYSSESD

$----Y P D D$

NPCLPHRNSDRDLNIRKWSSIAIN

GGLPSS-C

$----T S I$

---- GNFC 
bioRxiv preprint doi: https://doi.org/10.1101/716746; this version posted July 28, 2019. The copyright holder for this preprint (which was not certified by peer review) is the author/funder. All rights reserved. No reuse allowed without permission.

492 Figure 2.

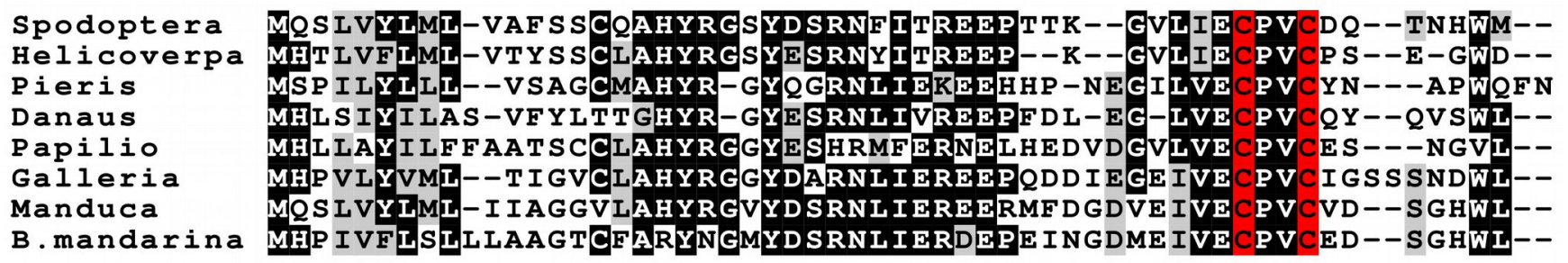

Spodoptera Helicoverpa

Pieris

Danaus

Papilio

Galleria

- ASTFD

A EVVC-IKEGDKSYKLCRFGTYINTACNNRLD

PDNGNP KCNITIEAQRYKKC

- - P TR FVCNITI GNKKYKRCRMGNYTNTVCGNRID

- - P THFH CNI I RGNKKY KR CEF GTYKNEVCGNRRD

- -PSNEI CPIVRGNKRYKRCQRGTYVNTVCDNRLD

- -PSNEECTIRKGNKKYKKC

EIGTYINEVCGNRRD

YSGP GEQCTEKREF DMYGKRCAP G

Manduca

B. mandarina

- TSNEVC

Spodoptera

Helicoverpa

Pieris

Danaus

Papilio

Galleria

YYCNKMEGVCTGLEFQLGNNWQWKMYP---YTGVRSELRNQPEDSKFSFEGVRN

Manduca

YECNQKEGVCTGPENRPEIYWPYRFGI---YPDRRSSSKSTAEE---AFEDMTN

YDCDF SYHVCTGIGFS IS I HDRLSF--PRLYP LRP LNEGENQA--KSMLLT

YDCDGTFHVCTGYGYT INSHMRWLLNHVSRYPGNQNDEQLREK- - ALYLA

$Y Y C D N L Y N V$ CV GLDYSVERP F G-IYNHLYQYP IRDDKL IV

YY CNRYLGVCT GL EYNVESKTQWIINPNRRYP IRAKRDV

B. mandarina

Y Y CNKLMGI CQGL EYVP DSTQQFLLNPHHRYSLQRSGIKTRAA--NHFLDT I RN

YYCNKPMGI CQ GMDYVLDSNE LFLLNPHRRYSLQRNTLKGPMS - - HS LIDAIRN 
bioRxiv preprint doi: https://doi.org/10.1101/716746; this version posted July 28, 2019. The copyright holder for this preprint (which was not certified by peer review) is the author/funder. All rights reserved. No reuse allowed without permission.

\section{Figure 3.}
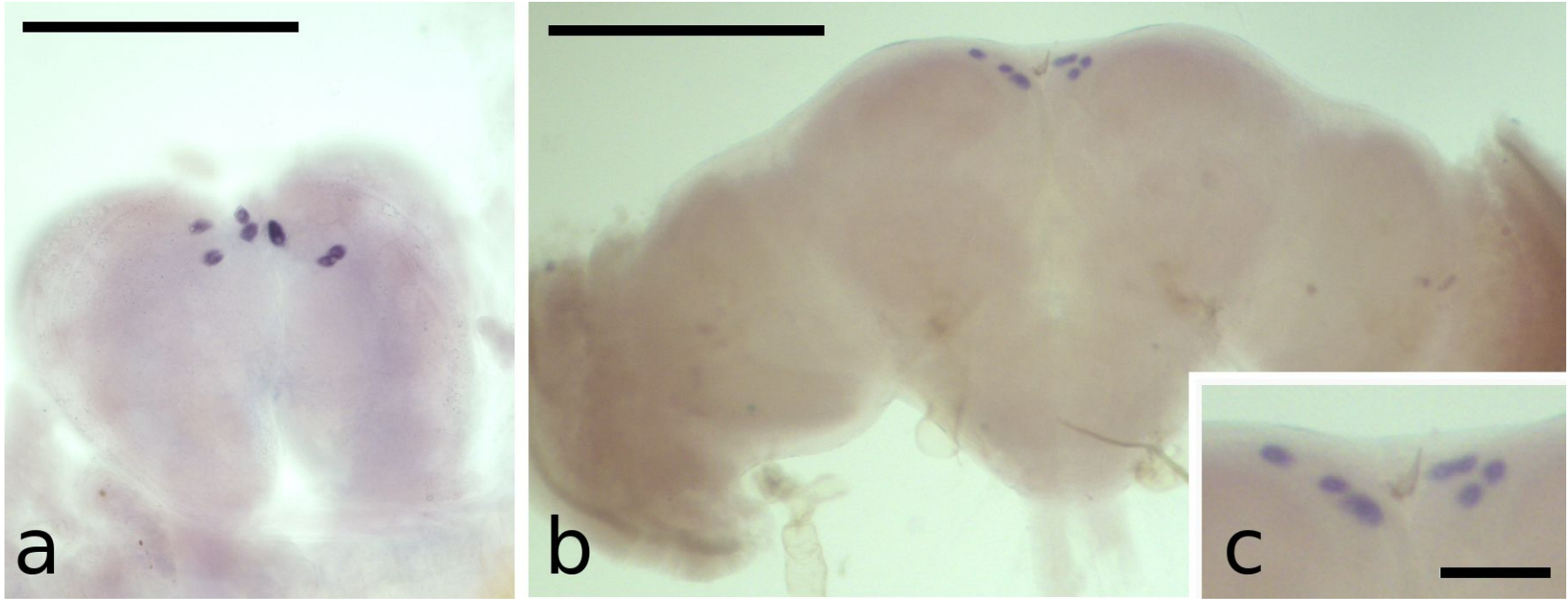
496 Figure 4.

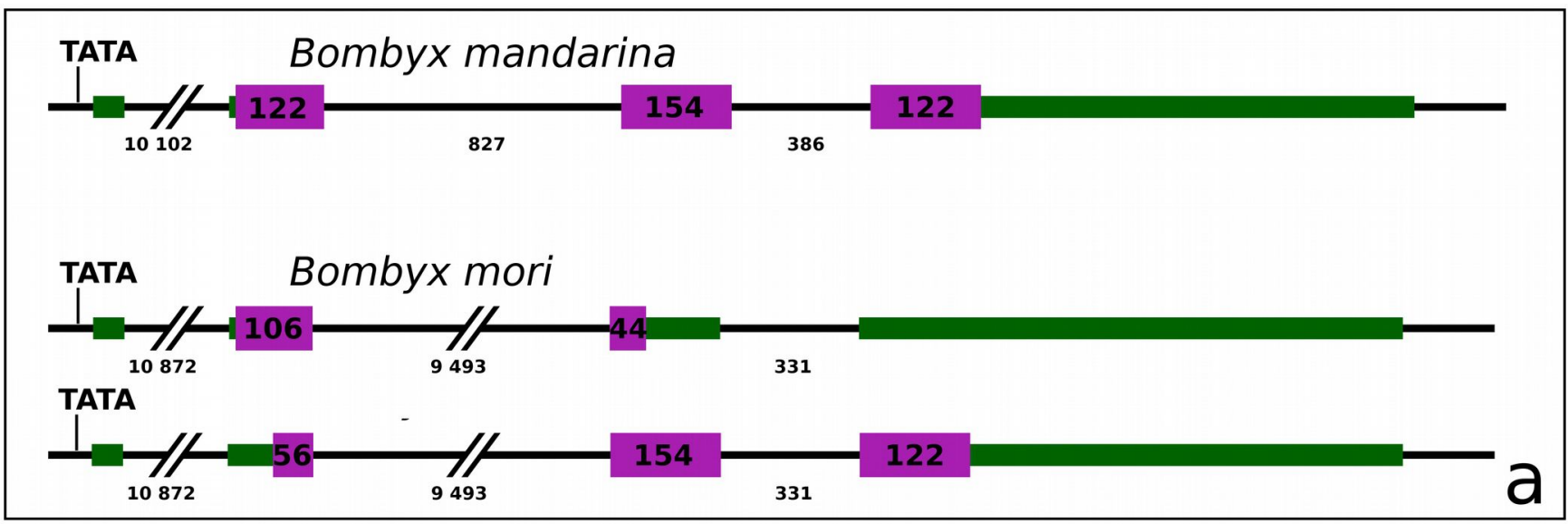

B. mandarina ttaaatttcagAAATCCACCAGTCATGCATCCTATCGTTTTCCTATCCCTGTTGCTGGCT

B. mori ttaaatttcagAAATCCATCAGTCATGCATCCTGTCGTTTTCCTATCCCTGTTGCTGGCT ******************* *************** $* * * * * * * * * * * * * * * * * * * * * * * * * * *$

B. mandarina

GCCGGAACATGCTTCGCTCGCTACAATGGAATGTATGACAGTCGCAACCTTATCGAGAGA

B. mori GCCGGAACAATGGAATGTATGACAGTCGCAACCTTATCGAGAGA $* * * * * *$ $* * * * * * * * * * * * * * * * * * * * * * * * * * * * * * * * * * * * * *$

B. mandarina GACGAACCGGAAATCAACGGTGACATgtgagattgcC

B. mori GACGAACCGGAAATCAACGGTGACATgtgagattgCC $* * * * * * * * * * * * * * * * * * * * * * * * * * * * * * * * * * * * *$

B. mandarina

B. mori-1

$\downarrow$

MHPIVFLSLLLAAGTCFARYNGMYDSRNLIERDEPEINGDMEIVECPVCEDSGHWLTSNE MHPVVFLSLLLAAGTMECMTVATLSRETNRKSTVTWKLSSVQFARTRVTG*

B. mori-2

$\uparrow \uparrow$ MYDSRNLIERDEPEINGDMEIVECPVCEDSGHWLTSNE

B. mandarina

B. mori-2

VCTIVKGHRKYKKCDHGTYINEVCGNRRDCFRGPGEQCTEKMEFDTYGQKCAPGYYCNKP VCTIIRGHRKYKKCDHGTYINEVCGNRRDCFRGPGEQCTEKMEFDTYGQKCAPGYYCNKP

B. mandarina MGICQGMDYVLDSNELFLLNPHRRYSLQRNTLKGPMSHSLLDAIRN*

B. mori-2 MGICQGMDYVLDSNELFLLNPHRRYSLQRNTLKGPMSHSLLDAIRN* 